DEMOGRAPHIC RESEARCH

VOLUME 38, ARTICLE 42, PAGES 1277-1302

PUBLISHED 10 APRIL 2018

http://www.demographic-research.org/Volumes/Vol38/42/

DOI: 10.4054/DemRes.2018.38.42

Research Article

Migration, legality, and fertility regulation:

Abortion and contraception among migrants and natives in Russia

Victor Agadjanian

Sam Hyun Yoo

(C) 2018 Victor Agadjanian \& Sam Hyun Yoo.

This open-access work is published under the terms of the Creative Commons Attribution 3.0 Germany (CC BY 3.0 DE), which permits use, reproduction, and distribution in any medium, provided the original author(s) and source are given credit.

See https://creativecommons.org/licenses/by/3.0/de/legalcode. 


\section{Contents}

$\begin{array}{lll}1 & \text { Introduction } & 1278\end{array}$

2 Background $\quad 1279$

3 Context 1280

3.1 Contraception and abortion in post-Soviet Eurasia 1280

$\begin{array}{ll}3.2 & \text { Migration to Russia } \\ \end{array}$

$4 \quad$ Conceptualization and hypotheses 1282

$5 \quad$ Data and methods $\quad 1284$

$\begin{array}{lll}5.1 & \text { Data } & 1284\end{array}$

$\begin{array}{lll}5.2 & \text { Method } & 1285\end{array}$

6 Results 1287

$\begin{array}{lll}6.1 & \text { Descriptive results } & 1287\end{array}$

$\begin{array}{lll}6.2 & \text { Multivariate results } & 1288\end{array}$

$7 \quad$ Discussion and conclusion 1292

8 Acknowledgments 1294

$\begin{array}{ll}\text { References } & 1295\end{array}$ 


\title{
Migration, legality, and fertility regulation: Abortion and contraception among migrants and natives in Russia
}

\author{
Victor Agadjanian ${ }^{1}$ \\ Sam Hyun Yoo ${ }^{2}$
}

\begin{abstract}
BACKGROUND

Migrant-vs.-native differentials in reproductive behavior are typically examined through the prism of socioeconomic and cultural constraints that characterize the migration process and experiences. However, the literature seldom factors in migrant legal status because necessary data is rarely available.
\end{abstract}

\section{OBJECTIVE}

The study seeks to fill this important gap by looking at variations in induced abortion and contraceptive use not only between migrants and nonmigrants but also among migrants of different legal statuses in the Russian Federation.

\section{METHODS}

We use unique survey data collected in urban Russia from Central Asian working migrant women of different legal statuses - regularized vs. irregular - as well as their native counterparts. Binomial and multinomial logistic regressions are fitted to model abortion experience and current contraceptive use and method choice.

\section{RESULTS}

The results point to higher overall use of abortion among natives, but also to significant differences between migrants with regularized and irregular legal statuses. With respect to contraception, while no variation in overall use between migrants and natives or between migrants of different legal statuses is detected, instructive migrant-vs.-native differences in method choice emerge.

\section{CONCLUSIONS}

The findings underscore the importance of migrants' legal status, along with their other characteristics, for a better understanding of their reproductive behavior and for more effective corresponding policies.

\footnotetext{
${ }^{1}$ University of Kansas, Lawrence, USA. Email: vag@ku.edu.

${ }^{2}$ Kongju National University, Chungcheongnam-do, Republic of Korea.
} 


\section{CONTRIBUTION}

The study offers pioneering insights into the intersection of migration, legality, and fertility in contemporary Russia and contributes to the cross-national scholarship on migration and reproductive behavior and health.

\section{Introduction}

A large body of cross-national scholarship has examined the association between international migration and fertility trends and levels. This scholarship typically looks at social disruptions caused by migration, which are usually associated with a decline in fertility immediately before and after the move, and at subsequent adaptation of migrants' fertility preferences and behavior to those dominant in host societies. In addition, migrants' premigration socialization as well as selection into migration, which are often related to distinct reproductive propensities, have been widely examined (e.g., Abbasi-Shavazi and McDonald 2000; Carter 2000; Mayer and Riphahn 2000; Lindstrom and Giorguli-Saucedo 2002; Andersson 2004; Parrado 2011). However, research on reproductive behavior of international migrants seldom looks into variations by legal status, largely because information about migrants' legal status is rarely collected in surveys. Yet, legal status is highly consequential for a wide range of international migrants' outcomes in the host country, including access to health care (e.g., Castañeda 2009; Viladich 2012; Willen 2012), and therefore may affect migrants' reproductive options and choices.

To address this gap in the literature, we examine induced abortion experience and contraceptive behavior among working native women and migrant women from Central Asia in the Russian Federation (hereafter also Russia), a major destination for international migrants that has received remarkably little attention from scholars of sexual and reproductive health. We use a unique data set which, in addition to comparing natives and migrants from Kyrgyzstan, Tajikistan, and Uzbekistan, allows us to distinguish between migrants of different legal statuses. ${ }^{3}$ Specifically, following earlier research (Agadjanian, Menjívar, and Zotova 2017), we compare two groups of migrant workers: Those who have Russian citizenship or permanent residence, whom we define as fully regularized, and those who have temporary residence status (obtained either legally or not) or who do not even have a temporary residential registration.

\footnotetext{
${ }^{3}$ Following the Russian convention, we use the term 'migrant' rather than 'immigrant' when referring to the Russian context.
} 


\section{Background}

In contrast to the substantial literature on native-vs.-migrant differentials in fertility outcomes, relatively little research has addressed such key proximate determinants of fertility as access to and utilization of abortion and contraceptive services. This research, however limited, points to instructive differences between migrants and natives. For example, a study in Sweden (Helström et al. 2003) found that immigrant women had higher induced abortion rates than Swedish-born women. In Finland, immigrants of several origins, such as the Baltics, Russia, Southeast Asia, and subSaharan Africa, had higher abortion rates than native Finnish women (Malin and Gissler 2008). Immigrants were also more likely to use abortion than natives in two recent Spanish studies (Rodriguez-Alvarez et al. 2016; González-Rábago et al. 2017). Immigrant women in the Netherlands were found to have higher risks of repeat abortions compared to native Dutch women (Picavet, Goenee, and Wijsen 2013). Looking for explanations of these differentials, a study in Denmark concluded that disproportionate use of abortion among immigrant women was largely attributable to their socioeconomic disadvantage and higher parity (Rasch et al. 2008). In the same vein, du Prey et al. (2014), who did not detect any significant immigrant-vs.-native differences in abortion in their study in Canada, suggested that this finding could be explained by a relatively high socioeconomic status of immigrants in their sample.

Use of induced abortion is related to contraceptive use. As several studies have demonstrated, contraceptive use among immigrant women can often be hindered by a combination of economic, cultural, and institutional barriers (Manderson et al. 2002; Betancourt, Colarossi, and Perez 2013; Farid et al. 2013; Poncet et al. 2013; Akerman et al. 2016). In the above-cited Swedish study by Helström et al. (2003), migrant women had lower contraceptive prevalence than did native women. Garcés-Palacio, Altarac, and Scarinci's (2008) study of low-income Latina immigrant and non-Latina women in a US setting found significantly lower contraceptive rates among the former.

The difference between migrants and natives, however, may not be only in overall contraceptive prevalence but also in contraceptive method choice. For example, White and Potter (2013), using nationally representative US data, found that Mexican-born immigrants tended to use less effective methods compared to nonimmigrants. Immigrant women seeking abortion in Canada reported lower levels of hormonal contraceptive method use at the time of pregnancy than did nonimmigrant women (Wiebe 2013). White and colleagues (2016) also observed relatively low use of hormonal contraception in their qualitative study of recent Latina immigrants in the United States South, which the authors attributed to various cultural and social barriers. Similarly, Alvarez-Nieto and colleagues (2015) noted that contraceptive choices of immigrant women in Spain were strongly affected by the cultural notions and norms in 
places of origin. Yet Quelopana, and Alcalde (2014) also argued that immigrant women in the United States context gradually adapt to reproductive health norms, including those related to contraceptive choices and practices, in the host society. And Gonzalez et al. (2010) did not find evidence of culturally rooted barriers to contraceptive use among recent Latina immigrants in the American Midwest.

In addition to socioeconomic and cultural characteristics, undocumented status may greatly limit migrants' access to basic reproductive services (Wolff et al. 2005; Schoevers, van den Muijsenbergh, and Lagro-Janssen 2010) and specifically to effective contraceptives (Casillas et al. 2015). For example, undocumented status, along with other disadvantages, was shown to constrain Mexican immigrants' access to abortion services in the United States (Deeb-Sossa and Billings 2014). However, research focusing on the role of legal status remains scarce, and it is typically qualitative in nature and is based on convenience samples. Hence, there is a great need for quantitative assessment of variations in reproductive behavior according to immigrant legal status to complement the insights of the qualitative scholarship.

\section{Context}

\subsection{Contraception and abortion in post-Soviet Eurasia}

Modern contraceptive use was low in the former Soviet Union (Popov, Visser, and Ketting 1993; Remmenick 1993). In the context of an overall low contraceptive prevalence, however, a relatively high prominence of the IUD - mainly because of almost total unavailability of hormonal contraception - was a peculiar part of the Soviet family planning culture, especially on the periphery of the Soviet empire, such as Central Asia (Popov, Visser, and Ketting 1993; Avdeed 1994). In the quarter century after the breakup of the USSR, contraceptive use, especially use of hormonal methods, has increased considerably in Soviet successor states but still remains low by Western standards. In Russia, for example, despite rising contraceptive prevalence, the unmet need for modern contraception is as high as $17 \%$ (Rosstat 2012: 25). Unmet need is comparable or higher in Central Asia: 18\% in Kyrgyzstan (KDHS 2013: 119) and 23\% in Tajikistan (TDHS 2013: 90) (no recent data on Uzbekistan is available). Notably, the IUD continues to dominate the contraceptive choice in the region: Based on most recent available data, among all currently married women aged 15-49 who reported using modern contraception, 66\% in Kyrgyzstan (KDHS 2013: 111), 72\% in Tajikistan, and $82 \%$ in Uzbekistan (UHES 2004: 57) were using the IUD. In contrast, only $25 \%$ of married modern contraceptive users in Russia opted for that method (Rosstat 2012: 21). 
The historically low levels of modern contraceptive use in the former Soviet Union are partly related to high reliance on induced abortion (Henshaw 1986; Popov 1991; Remennick 1991, 1993). Legalized in 1955, abortion on request was widely available and used, especially in the European parts of the USSR and the European-origin population in its Asian parts (Popov 1991; Remennick 1991; Mogilevkina et al. 1996; Agadjanian and Qian 1997). Post-Soviet Russia has seen growing opposition to abortion, most forcefully voiced by the religious establishment of all faiths and often echoed by the government officialdom concerned about low rates of population growth (Denisov and Sakevich 2014). Official statistics and surveys show a continuous decline in abortion rates throughout the post-Soviet era (Denisov and Sakevich 2014; Philipov et al. 2004). Yet, abortion has remained a major method of fertility regulation in Russia and other parts of post-Soviet Eurasia, even though studies point to increasing variations in abortion rates across the Soviet successor states (David and Popov 1999; Agadjanian 2002; Denisov, Sakevich, and Jasilioniene 2012).

Official abortion statistics from the former Soviet Union should be used with caution, as they may underestimate abortions performed by private providers and selfadministered medication abortions (e.g., Jilozian and Agadjanian 2016). However, assuming that the undercount of abortions does not vary dramatically across post-Soviet settings, the available statistics point to a sharp contrast in abortion levels between Russia and other post-Soviet states, especially those in Central Asia: While the abortion rate in Russia is as high as 38 abortions per 1,000 women of reproductive age, it is 16, 11, and 5 abortion per 1,000 women in Kyrgyzstan, Tajikistan, and Uzbekistan, respectively (Sedgh et al. 2011: 88).

\subsection{Migration to Russia}

After the dissolution of the USSR, the Russian Federation has become a major destination for international migration and currently hosts, according to different estimates, either the second largest (Ratha, Eigen-Zucchi, and Plaza 2015) or the third largest (United Nations 2016) number of international migrants. The majority of international migrants in Russia come from the countries that once were part of the Soviet Union, with three predominantly Muslim nations of Central Asia - Kyrgyzstan (population of 6 million), Tajikistan (9 million), and Uzbekistan (32 million) accounting for a large and growing share. Because citizens of those nations do not need a visa to enter the Russian Federation, many Central Asians come to Russia, at least initially, as tourists or private visitors, before starting to work. Moscow, the Russian capital and by far the largest city, has been a primary magnet for these migrants, but the destinations of migration flows have been diversifying to include other Russian cities. 
Labor migration from Central Asia began almost exclusively as male, but women have come to constitute an increasingly large share of the migration flow (Tyurukanova 2011; Khusenova 2013; Rocheva and Varshaver 2017). Because pathways to legal work, permanent residence, and ultimately Russian citizenship (for those who seek it) are complex and costly, many Central Asian migrants, men and women alike, have temporary status, often with numerous legal irregularities (e.g., lacking migration registration, residential registration, or work permit) and therefore are often marginalized, harassed, and exploited by their employers and law enforcement officials (Reeves 2013a; 2013b; Abashin 2014; Malakhov 2014; Gorina, Agadjanian, and Zotova 2017). Central Asian migrants' ethno-racial background (most are darkerskinned and are phenotypically distinct from the majority of Russians, and many have poor command of the Russian language) and religion (most, if not all, are Muslim) add to their economic and legal marginalization (Zakharov 2015; Agadjanian, Menjívar, and Zotova 2017). While some migrants from Central Asia manage to obtain Russian citizenship, many intend to return to their home countries after working in Russia (Agadjanian, Gorina, and Menjívar 2014). ${ }^{4}$

Reproductive health care services, including abortion procedures and family planning consultations, are - in principle - available free of charge to Russian citizens and permanent residents through the national Compulsory Medical Insurance (CMI). Although CMI does not cover contraceptives or medical abortion drugs (Methotrexate/Misoprostol), the quality of care is uneven, and patients are often forced to pay for additional services both officially and informally. Russian citizens and permanent residents are at a great advantage compared to temporary and irregular migrants, who are excluded from most public health sector services and typically must resort to expensive fee-based private providers. ${ }^{5}$ These differential constraints could have implications for migrants' access to and use of reproductive health information and services.

\section{Conceptualization and hypotheses}

Our conceptual model engages the insights from the reviewed cross-national literature on abortion and contraception among international migrants and on the role of legal status in access to abortion and contraceptive services. At the same time, it adapts these

\footnotetext{
${ }^{4}$ The data used in this study was collected before Kyrgyzstan's ascension to the Russia-led Eurasian Economic Union, which has facilitated Kyrgyzstani citizens' entry into and employment in the Russian Federation.

${ }^{5}$ Abortion services were included in the general gynecological and reproductive service license for private providers until 2017. Starting in 2017 , private providers are required to apply for a separate license to offer abortion services.
} 
insights to the post-Soviet reproductive, cultural, and institutional context and to the particularities of international migrants' legal experiences in the Russian Federation. The reviewed literature typically suggests that migrants would have higher abortion rates and lower contraceptive rates than native women. However, this might not be the case in the context of post-Soviet Russia, where induced abortion, despite growing religious and official disapproval, remains widely acceptable and used. In fact, given greater traditionalism of Central Asian migrants compared to natives (i.e., mainly ethnic Russians) and the long history of ethnic differentials in abortion use, migrant women may have lower use of induced abortion than native Russian women. At the same time, fully regularized migrants (i.e., those with Russian citizenship or permanent residence) may have greater abortion use than migrants in more precarious legal positions, as such status offers access to free or highly subsidized abortion services in the public health sector. Citizenship and permanent residence status may also connote greater integration into Russian reproductive mores, including the persistent presence of what some researchers labeled as 'abortion culture' (Stloukal 1999; Agadjanian 2002).

The second part of our analysis is focused on modern contraception. While acknowledging the role of traditional contraception for fertility regulation, the focus on modern contraception (hereafter also simply contraception) is particular important given the above noted connection between access to modern contraceptives and legal status. With respect to modern contraception, the reviewed literature, with few exceptions (e.g., Gonzalez et al. 2010; Quelopana and Alcalde 2014), tends to find lower contraceptive prevalence among migrants compared to natives. Although comparable evidence from Russia is lacking, overall, there is no reason to expect that the migrant-vs.-native differential in contraceptive prevalence should deviate from this pattern. Fully regularized legal status, however, may facilitate access to contraception, and corresponding differences among migrants should be expected. At the same time, the historic-cultural legacies may imprint the method choice, with migrants gravitating to more familiar and established options, which in the post-Soviet context are represented primarily by the IUD, while natives favoring 'newer' (even if not more effective) methods such as the pill and condoms. Again, fully regularized status may bridge these divergent method preferences, pushing migrants toward method choices that are dominant among the native population.

The above assumptions yield the following key general hypotheses. With respect to induced abortion, we first hypothesize that Central Asian migrant women are less likely to have had an induced abortion, compared to native Russian women (Hypothesis 1a). We also hypothesize that fully regularized migrants are more likely to have had an induced abortion, compared to migrants of temporary or irregular status (Hypothesis $1 b)$. 
With regard to modern contraception, we test three hypotheses. First, we hypothesize that migrants are generally less likely to use contraception, compared to natives (Hypothesis 2a). We also hypothesize that fully regularized migrants are more likely to use contraception, compared to temporary and irregular migrants (Hypothesis $2 b)$. Finally, we test two hypotheses regarding contraceptive method choice. First, we hypothesize that migrants overall are more likely to use long-acting methods, especially the IUD, while natives are more likely to use short-acting contraceptives, such as hormonal pills or condoms (Hypothesis 2c). However, assuming different degrees of assimilation of the two migrant subgroups into Russian contraceptive mores, we also expect that temporary/irregular migrants are more likely to choose long-term methods over short-term ones, compared to fully regularized migrants (Hypothesis $2 \mathrm{~d}$ ).

\section{Data and methods}

\subsection{Data}

Data used in this study comes from a survey of working women conducted in 20122013. The survey was carried out at two main sites, the cities of Moscow and Novosibirsk, and an additional site, the city of Yekaterinburg. The survey sample totaled 940 women aged 18-40 and included representatives of three migrant ethnic groups - Kyrgyz, Tajik, and Uzbek - as well as a control group of nonmigrant (native) women. Because the vast majority of female Central Asian migrants work in eateries (mainly as waitresses and cleaners), semi-formal produce and clothing bazaars (as stall owners and/or vendors), and formal retail and grocery stores (as sales clerks and cleaners), the survey focused on women working in these industries.

Conventional, household-based approaches to sampling international migrants are not feasible in the Russian context. Instead, to sample women working in eateries and formal retail, a time-venue approach was used. A three-stage sampling procedure was implemented. At the first stage, each city's territory was parceled into squares of approximately $5 \mathrm{~km}^{2}$. In a randomly selected sample of these squares all eateries and retail outlets were recorded. At the second stage, eateries and retail outlets were randomly selected from the lists. At the final stage, women aged 18-40 who were migrants from the three Central Asian groups and nonmigrants (the control subsample) working at the selected establishments were approached for a survey interview at approximately the same time of day (if more than one eligible woman worked at a given establishment, one was randomly selected). ${ }^{6}$

\footnotetext{
${ }^{6}$ See Agadjanian and Zotova (2012) for a detailed description of applying a time-venue approach to sample and recruit migrants in the context of urban Russia.
} 
To sample women working in bazaars, first, bazaars were randomly selected from the complete list of each city's bazaars. Then in each selected bazaar, a target number of women was chosen using a random-walk algorithm (if the selected bazaars did not yield the target number of respondents of each ethno-provenance, additional bazaars were added). As a result of this sampling procedure, approximately one-third of the sample in the two main sites, Moscow and Novosibirsk, came from each of the three types of workplace - retail, eateries, and bazaars. In Yekaterinburg, a complementary site, only women working in bazaars were included. In all three sites, the sample was more or less evenly split among the four ethno-provenance groups. The overall survey participation rate was $61 \%$, and it was higher among migrants (78\%) than among natives (39\%).

All survey participants were administered a fully structured questionnaire through a face-to-face interview in the language and place of their choice. All interviewers were themselves migrants from the three countries and were matched with respondents by ethnicity and language, which helped build the interviewer-respondent rapport and thus improve the quality and reliability of reporting, especially on such potentially sensitive matters as legality, income, or reproductive history (Zotova and Agadjanian 2014). The survey instrument included questions on respondents' sociodemographic background, ethnocultural and socioeconomic characteristics, reproductive and migration history, and legal status, among others. The survey design, instrument, and procedures were approved by the Institutional Review Board of Arizona State University and the Ethics Committee of the Institute of Ethnology and Anthropology of the Russian Academy of Sciences.

\subsection{Method}

Outcomes and predictor. The outcomes of interest are: (1) Whether or not a respondent had at least one induced abortion (a dichotomy, separating those who had at least one abortion from those who never had one); (2) Whether or not a migrant respondent had at least one abortion since her migration to Russia (the corresponding analysis excludes natives); (3) Current use of modern contraception overall (a dichotomy - using a method vs. not using a method); and (4) Current use of modern contraception by type of method (a trichotomy that separates nonusers from users of short-term methods, such as the pill or condom, and from users of long-term methods, mainly the IUD but also tubal ligation).

Migration/legal status is the predictor. To test our hypotheses, we follow an earlier approach (Agadjanian, Menjívar, and Zotova 2017) to subdivide respondents into three groups: native Russians (regardless of prior experience of internal migration); migrants 
who are Russian citizens or permanent residents (fully regularized migrants); and migrants who have temporary or irregular status. As argued earlier, Russian citizenship or permanent residence status, in addition to allowing full access to state health services, can also be seen as a marker of migrants' exposure to dominant Russian sexual and reproductive mores.

Models. Logistic regression for binary outcomes is used for the multivariate analysis of abortion experience. We start with a model for the entire sample $(n=940)$, in which we contrast Russian natives, migrants with Russian citizenship/permanent residence, and temporary/irregular migrants. This model controls for respondents' age groups: under 26, 26-30, 31-35, and 36-40. It also controls for the number of living children and for coresident marital partnership. Education is included as a set of dummies: high school or less, vocational school, and at least some university education. The model also controls for the sector of work, which by design includes three categories - retail, eateries, and bazaars - and occupational type, which is operationalized as a dichotomy - higher-status occupations (e.g., sales clerk, chef, bazaar stall owner) vs. lower-status occupations (e.g., cleaner, dishwasher, stall owner's helper). Total monthly income in Russian rubles and the type of earnings - fully official (i.e., processed entirely through payroll or fully reported to tax authorities) vs. at least partly nonofficial - are also controlled for. Finally, the model controls for the data collection site - Moscow vs. Novosibirsk/Yekaterinburg.

We then fit a model for the migrant subsample only $(n=694)$; in addition to the covariates included in the previous model, this model controls for migrants' ethnoprovenance (Kyrgyz, Tajik, or Uzbek) and for the duration of migrants' stay in Russia (duration since most recent migration for women who reported multiple prolonged spells in the country). This model also controls for abortion experience prior to migration (whether the respondent had at least one abortion before coming to Russia).

For the analysis of current contraceptive use, we also employ logistic regression. First, we fit a binomial model predicting whether respondents currently use any modern contraceptive method. The analytic sample is limited to nonpregnant respondents who considered themselves fecund $(\mathrm{n}=884)$. The model includes the same covariates as in the first abortion model above, as well as recent exposure to sexual intercourse. The second binomial model is restricted to migrants only $(n=644)$ and includes, in addition to the same controls, ethno-provenance and duration of stay in Russia since the most recent migration. Finally, we fit method-specific models. In these models, contraceptive use is operationalized as a trichotomy - none, a short-term method, and a long-term method; accordingly, multinomial logistic regression is used. Again, we fit two models: one for the entire sample and another for migrants only (also adding controls for ethnoprovenance and length of stay in Russia). 
In the following section, we begin with a presentation of the descriptive analysis of induced abortion and contraceptive use across the three migration/legal-status groups. We then present the results of multivariate models for the two outcomes of interest.

\section{Results}

\subsection{Descriptive results}

Induced abortion. Table 1 displays the percentage of women who had at least one abortion and shares of pregnancies ending in induced abortion by nativity and legal status. Native women clearly stand out: They had 0.85 abortions on average, and fully one-third of them had at least one abortion in their lifetimes. Slightly over half of their pregnancies were aborted, more than double the rate among migrants. Yet, intriguing differences within the migrant subsample also emerge. Fully regularized migrants aborted a noticeably higher share of their pregnancies and comprised a much higher fraction of those who had at least one abortion than did their temporary/irregular counterparts. Also, notably, while this general pattern holds for both premigration and postmigration pregnancies, the contrast between the two subgroups of migrants appears starker in the after-migration period.

Table 1: Induced abortion experience by nativity and legal status

\begin{tabular}{|c|c|c|c|c|c|c|}
\hline & \multirow[t]{2}{*}{$\mathbf{N}$} & \multirow{2}{*}{$\begin{array}{l}\text { Percent of pregnancies } \\
\text { ending in abortion } \\
\text { (abortions/pregnancies) }\end{array}$} & \multirow[t]{2}{*}{$\begin{array}{l}\text { Mean number } \\
\text { of abortions }\end{array}$} & \multicolumn{3}{|c|}{$\begin{array}{l}\text { Percent of women who have had at least } \\
\text { one abortion (number) }\end{array}$} \\
\hline & & & & In lifetime & $\begin{array}{l}\text { Before } \\
\text { migration }\end{array}$ & $\begin{array}{l}\text { After } \\
\text { migration }\end{array}$ \\
\hline $\begin{array}{l}\text { Temporary or } \\
\text { irregular migrants }\end{array}$ & 509 & $\begin{array}{c}16.4 \\
(134 / 819)\end{array}$ & 0.26 & $\begin{array}{l}13.2 \\
(67)\end{array}$ & $\begin{array}{l}10.2 \\
(52)\end{array}$ & $\begin{array}{l}3.9 \\
(20)\end{array}$ \\
\hline $\begin{array}{l}\text { Fully regularized } \\
\text { migrants }\end{array}$ & 185 & $\begin{array}{c}23.5 \\
(87 / 371)\end{array}$ & 0.47 & $\begin{array}{l}26.5 \\
(49)\end{array}$ & $\begin{array}{l}16.2 \\
(30)\end{array}$ & $\begin{array}{l}12.4 \\
(23)\end{array}$ \\
\hline Natives & 246 & $\begin{array}{c}50.2 \\
(210 / 418)\end{array}$ & 0.85 & $\begin{array}{l}33.7 \\
(83)\end{array}$ & $\mathrm{n} / \mathrm{a}$ & $\mathrm{n} / \mathrm{a}$ \\
\hline Total & 940 & $\begin{array}{c}26.8 \\
(431 / 1,608)\end{array}$ & 0.46 & $\begin{array}{l}21.2 \\
(199)\end{array}$ & $\begin{array}{l}11.8 \\
(82)\end{array}$ & $\begin{array}{l}6.2 \\
(43)\end{array}$ \\
\hline
\end{tabular}

Contraceptive use. Table 2 shows current contraceptive prevalence in the three migration/legal-status groups. All three groups have comparable levels of overall contraceptive use, clustering around the sample average of $42.1 \%$. However, when we disaggregate contraceptive use by type of method, we see a stark contrast between native Russians, who greatly favor short-term methods (mainly condoms but also the 
pill), and migrants, who use both short-term methods and long-term methods (overwhelmingly the IUD but also two cases of tubal ligation). This pattern fits with the higher use of induced abortion among native women. Differences between the two migrant subgroups - somewhat greater reliance on short-term methods among fully regularized migrants vs. higher use of longer-term methods by temporary/irregular migrants - can also be observed.

Table 2: Current contraceptive use by nativity and legal status

\begin{tabular}{lccccc}
\hline & None/traditional & \multicolumn{3}{c}{ Modern methods } & Total \\
& $\%$ & Subtotal & Long-term & Short-term & \\
& $\%$ & $\%$ & $\%$ & $\mathrm{~N}$ \\
\hline Temporary or irregular migrants & 58.3 & 41.7 & 28.1 & 13.6 & 477 \\
Fully regularized migrants & 55.1 & 44.9 & 20.4 & 24.6 & 167 \\
Natives & 59.2 & 40.8 & 0.8 & 40.0 & 240 \\
\hline Total & 57.9 & 42.1 & 19.2 & 22.9 & 884 \\
\hline
\end{tabular}

Note: Infecund and currently pregnant excluded.

\subsection{Multivariate results}

Induced abortion. The results of a logistic regression model predicting the likelihood of having ever had at least one abortion are presented in Table 3, Section A. These results align with the descriptive results (Table 1) in producing a stark contrast across the three legal-status groups, with nonmigrants showing the highest likelihood of having had at least one abortion and temporary/irregular migrants the lowest. As the parameter estimates suggest, compared to regularized migrants (the reference group), Russian natives have 2.4 times higher odds of experiencing an abortion in their lifetime (OR: $\exp (0.88)=2.41)$ while the odds of having had an abortion are $59 \%$ lower among temporary/irregular migrants $(\mathrm{OR}$ : $\exp (-0.89)=0.41)$. The model displayed in Section B.1 of Table 3 restricts the analysis to the migrant subsample. The gap between temporary/irregular and fully regularized migrants is only slightly smaller than in the previous model $(\mathrm{OR}$ : $\exp (-0.76)=0.41)$ and remains statistically significant. These results support our hypotheses H1a and H1b. 
Table 3: Logistic regression of having had at least one abortion among all women and migrants only (before and after migration)

\begin{tabular}{|c|c|c|c|c|c|c|c|c|}
\hline & \multicolumn{2}{|c|}{ A. All women } & \multicolumn{6}{|c|}{ B. Migrants only } \\
\hline & \multirow[b]{2}{*}{ Est. } & \multirow[b]{2}{*}{ SE } & \multicolumn{2}{|c|}{ 1. In lifetime } & \multicolumn{2}{|c|}{ 2. Before migration } & \multicolumn{2}{|c|}{ 3. After migratior } \\
\hline & & & Est. & SE & Est. & SE & Est. & SE \\
\hline \multicolumn{9}{|l|}{ Migratory/legal status } \\
\hline \multicolumn{9}{|l|}{ (Ref.: fully regularized migrant) } \\
\hline Temporary/irregular migrant & -0.89 & $0.25^{n}$ & -0.76 & $0.30^{\circ}$ & -0.52 & 0.35 & -0.89 & $0.43^{\prime}$ \\
\hline Native & 0.88 & $0.25^{n}$ & $\mathrm{n} / \mathrm{a}$ & $\mathrm{n} / \mathrm{a}$ & $\mathrm{n} / \mathrm{a}$ & $\mathrm{n} / \mathrm{a}$ & $\mathrm{n} / \mathrm{a}$ & $\mathrm{n} / \mathrm{a}$ \\
\hline \multicolumn{9}{|l|}{ Demographics } \\
\hline \multicolumn{9}{|l|}{ Age (ref.: <26) } \\
\hline Age $26-30$ & 1.04 & $0.32^{n}$ & 1.12 & $0.45^{\circ}$ & 1.49 & $0.61^{\circ}$ & 0.74 & 0.60 \\
\hline Age $31-35$ & 1.55 & $0.32^{n}$ & 1.85 & $0.45^{n}$ & 2.41 & $0.60^{-\cdots}$ & 0.91 & 0.63 \\
\hline Age $36-40$ & 1.30 & $0.34^{n \prime}$ & 1.31 & $0.50^{n}$ & 2.31 & $0.65^{\prime \prime}$ & -0.06 & 0.73 \\
\hline \multicolumn{9}{|l|}{ Education (ref.: high school or less) } \\
\hline Vocational school & -0.09 & 0.22 & -0.20 & 0.28 & -0.07 & 0.32 & -0.15 & 0.42 \\
\hline Some university or more & -0.20 & 0.24 & -0.17 & 0.31 & -0.37 & 0.36 & 0.20 & 0.43 \\
\hline Number of children ever born & 0.47 & $0.09^{\pi \times}$ & 0.49 & $0.12^{\pi \pi}$ & 0.39 & $0.13^{x x}$ & 0.43 & $0.17^{\pi}$ \\
\hline $\begin{array}{l}\text { Coresident partner } \\
\text { (ref.: no absent partner) }\end{array}$ & -0.28 & 0.18 & -0.56 & 0.24 & -0.72 & $0.28^{\prime \prime}$ & -0.02 & 0.35 \\
\hline Ethno-provenance (ref: Tajik) & $\mathrm{n} / \mathrm{a}$ & $\mathrm{n} / \mathrm{a}$ & & & & & & \\
\hline Kyrgyz & $\mathrm{n} / \mathrm{a}$ & $\mathrm{n} / \mathrm{a}$ & 1.59 & $0.36^{\prime \prime}$ & 2.14 & $0.47^{n}$ & 0.62 & 0.52 \\
\hline Uzbek & $\mathrm{n} / \mathrm{a}$ & $\mathrm{n} / \mathrm{a}$ & 1.18 & $0.35^{n}$ & 1.42 & 0.46 & 1.06 & $0.49^{\circ}$ \\
\hline \multicolumn{9}{|l|}{ Work and income } \\
\hline \multicolumn{9}{|l|}{ Work place (ref.: bazaar) } \\
\hline Retail & -0.53 & $0.23^{\circ}$ & -1.01 & $0.33^{n}$ & -1.18 & 0.39 & -0.32 & 0.45 \\
\hline Eatery & -0.52 & $0.25^{\circ}$ & -0.77 & $0.33^{\circ}$ & -1.18 & $0.41 “$ & -0.12 & 0.48 \\
\hline $\begin{array}{l}\text { Higher-status occupation } \\
\text { (ref.: lower-status) }\end{array}$ & 0.07 & 0.27 & -0.38 & 0.39 & 0.31 & 0.44 & -1.14 & $0.63^{\dagger}$ \\
\hline $\begin{array}{l}\text { All earnings are paid officially } \\
\text { (ref.: not all are) }\end{array}$ & -0.07 & 0.22 & 0.17 & 0.29 & 0.51 & 0.34 & -0.16 & 0.43 \\
\hline Total monthly income (RUR) & 0.00 & 0.01 & 0.00 & 0.01 & -0.01 & 0.02 & 0.01 & 0.02 \\
\hline \multicolumn{9}{|l|}{ Other } \\
\hline Years lived in Russia & $\mathrm{n} / \mathrm{a}$ & $\mathrm{n} / \mathrm{a}$ & -0.02 & 0.04 & -0.07 & 0.04 & 0.04 & 0.04 \\
\hline $\begin{array}{l}\text { Had abortion before migration } \\
\text { (ref.: no abortion) }\end{array}$ & $\mathrm{n} / \mathrm{a}$ & $\mathrm{n} / \mathrm{a}$ & $\mathrm{n} / \mathrm{a}$ & $\mathrm{n} / \mathrm{a}$ & $\mathrm{n} / \mathrm{a}$ & $\mathrm{n} / \mathrm{a}$ & 0.17 & 0.44 \\
\hline $\begin{array}{l}\text { Lives in Moscow } \\
\text { (ref.: Novosibirsk/Yekaterinburg) }\end{array}$ & 0.08 & 0.20 & -0.10 & 0.26 & 0.24 & 0.31 & -0.68 & $0.38^{\dagger}$ \\
\hline Intercept & -2.37 & $0.39^{\pi \pi}$ & -3.04 & $0.61^{\pi \pi}$ & -4.24 & $0.82^{x x}$ & -3.77 & $0.83^{\pi \pi}$ \\
\hline -2Log Likelihood & \multicolumn{2}{|c|}{814.45} & \multicolumn{2}{|c|}{494.01} & \multicolumn{2}{|c|}{383.57} & \multicolumn{2}{|c|}{276.75} \\
\hline $\begin{array}{l}\text { Number of cases } \\
\text { (number of induced abortions) }\end{array}$ & \multicolumn{2}{|c|}{940 (199) } & \multicolumn{2}{|c|}{694 (116) } & \multicolumn{2}{|c|}{$694(82)$} & \multicolumn{2}{|c|}{$694(43)$} \\
\hline
\end{tabular}

Note: Significance levels: ${ }^{\dagger} p<0.10,{ }^{*} p<0.05,{ }^{* *} p<0.01$; n/a not applicable. 
Next, we compare the induced abortion experience of fully regularized and temporary/irregular migrants before and after coming to Russia. The results of the corresponding pair of logistic regressions are presented in Sections B.2 and B.3 of Table 3. The results show no statistically significant difference between the two categories of women in before-migration experience. In contrast, the difference in the probability of postmigration abortion between the two groups is significant: temporary/irregular migrants are less likely than their fully regularized counterparts to have had an abortion since their arrival in the Russian Federation after controlling for other factors, including the length of stay in Russia. This result gives additional credence to H1b.

Among the effects of other covariates, we note a negative effect of coresident partnership (except in the postmigration model). Education and income do not show any net association with abortion experience, nor does the length of migrants' stay in Russia. Differences across the work sectors and ethnocultural differences are also present, but their explanation requires special investigation.

Contraceptive use. We start the multivariate analysis of current contraceptive use by fitting two binomial logistic regression models predicting the likelihood of current modern contraceptive use - one for the entire sample and one for the migrant-only subsample. The models produce no significant differences across the three migration/legal-status categories (results are not shown but are available upon request). Hypotheses $\mathrm{H} 2 \mathrm{a}$ and $\mathrm{H} 2 \mathrm{~b}$ are therefore not supported. We then fit a multinomial logistic regression in which the outcome can take one of three values - not using, using a short-term method (mainly the pill or condom), and using a long-term method (mainly the IUD). Table 4 displays the results of this model for all women. The model shows no statistically significant difference between the two subgroups of migrants but a pronounced contrast between migrants, whichever their legal status, and natives. Confirming the bivariate patterns, natives are significantly more likely to opt for shortterm methods than long-term methods compared to either migrant subgroup, regardless of age, education, partnership characteristics, sexual frequency, work-related characteristics, and place of residence. Yet, contrary to the pattern suggested in the descriptive analysis, the net difference between the two migrant subgroups is small and not statistically significant. Finally, we fit the same model for migrants only: This model confirms the similarity between fully regularized and temporary/irregular migrants in contraceptive method preference (results are not shown but are available upon request). The results lend support to hypothesis $\mathrm{H} 2 \mathrm{c}$ but not $\mathrm{H} 2 \mathrm{~d}$. 
Table 4: Multinomial logistic regression of contraceptive method type (none/short/long-term), all women

\begin{tabular}{|c|c|c|c|c|c|c|}
\hline & \multicolumn{2}{|c|}{ Short-term vs none } & \multicolumn{2}{|c|}{ Long-term vs none } & \multicolumn{2}{|c|}{$\begin{array}{l}\text { Long-term vs short- } \\
\text { term }\end{array}$} \\
\hline & Est & SE & Est & SE & Est & SE \\
\hline \multicolumn{7}{|l|}{ Migratory/legal status } \\
\hline \multicolumn{7}{|l|}{ (ref.: fully regularized migrant) } \\
\hline Temporary/irregular migrant & -0.08 & 0.28 & 0.08 & 0.33 & 0.16 & 0.34 \\
\hline Native & 0.57 & $0.28^{*}$ & -3.21 & $0.78^{* *}$ & -3.78 & $0.79^{* *}$ \\
\hline \multicolumn{7}{|l|}{ Demographics } \\
\hline \multicolumn{7}{|l|}{ Age (ref.: <26) } \\
\hline Age $26-30$ & 0.05 & 0.26 & 0.66 & 0.42 & 0.61 & 0.44 \\
\hline Age $31-35$ & -0.40 & 0.31 & -0.12 & 0.45 & 0.28 & 0.48 \\
\hline Age $36-40$ & -0.52 & 0.32 & -0.06 & 0.46 & 0.46 & 0.50 \\
\hline \multicolumn{7}{|l|}{ Education (ref.: high school or less) } \\
\hline Vocational school & 0.61 & $0.25^{*}$ & 0.55 & $0.28^{\dagger}$ & -0.05 & 0.32 \\
\hline Some university or more & 0.84 & $0.25^{* *}$ & -0.28 & 0.33 & -1.11 & $0.36^{* *}$ \\
\hline Number of children ever born & 0.60 & $0.12^{* *}$ & 1.28 & $0.14^{* *}$ & 0.68 & $0.15^{* *}$ \\
\hline $\begin{array}{l}\text { Coresident partner } \\
\text { (ref.: no partner or elsewhere) }\end{array}$ & 0.82 & $0.21^{\pi *}$ & 1.44 & $0.29^{-x x}$ & 0.62 & $0.31^{*}$ \\
\hline \multicolumn{7}{|l|}{ Work and Income } \\
\hline \multicolumn{7}{|l|}{ Work sector (ref.: bazaar) } \\
\hline Retail & -0.22 & 0.25 & 0.08 & 0.34 & 0.31 & 0.36 \\
\hline Eatery & -0.04 & 0.25 & 0.13 & 0.34 & 0.17 & 0.37 \\
\hline $\begin{array}{l}\text { Higher-status occupation } \\
\text { (ref.: Lower-status) }\end{array}$ & 0.76 & $0.27^{* \pi}$ & 0.53 & 0.43 & -0.23 & 0.43 \\
\hline $\begin{array}{l}\text { All earnings are paid officially } \\
\text { (ref.: not all earnings) }\end{array}$ & -0.17 & 0.23 & -0.19 & 0.29 & -0.02 & 0.32 \\
\hline Total monthly income (RUR) & 0.00 & 0.01 & -0.03 & $0.02^{\dagger}$ & -0.03 & $0.02^{\dagger}$ \\
\hline \multicolumn{7}{|l|}{ Other } \\
\hline $\begin{array}{l}\text { Had no sexual intercourse recently } \\
\text { (ref.: had intercourse recently) }\end{array}$ & -2.46 & $0.55^{* x}$ & -1.96 & $0.46^{\mathrm{m}}$ & 0.50 & 0.67 \\
\hline $\begin{array}{l}\text { Lives in Moscow } \\
\text { (ref: Novosibirsk/Yekaterinburg) }\end{array}$ & -0.16 & 0.21 & 1.93 & $0.32^{* \pi}$ & 2.09 & $0.34^{\pi *}$ \\
\hline Intercept & -2.11 & $0.37^{* *}$ & -4.31 & $0.62^{* *}$ & -2.20 & $0.65^{* *}$ \\
\hline -2 Log Likelihood & \multicolumn{6}{|c|}{$1,168.87$} \\
\hline Number of cases & \multicolumn{6}{|c|}{884} \\
\hline
\end{tabular}

Note: Fecund (self-assessed) and not pregnant women only; significance levels: ${ }^{\dagger} p<0.10,{ }^{*} p<0.05,{ }^{* *} p<0.01$. 
Among notable effects of other covariates, some university education is associated with preference for short-term methods, as is higher-status occupation. Women in permanent partnerships, while more likely to use modern contraception overall, were also more inclined to using long-term rather than short-term methods. Respondents interviewed in the capital city were more likely to favor long-term methods than those surveyed in the provincial sites. No age difference in method choice could be observed.

\section{Discussion and conclusion}

Our study adds to the literature on migration and reproductive behavior by focusing on a major, yet understudied, migrant-receiving context and exploring variations in abortion and contraception not only between migrants and nonmigrants but also across categories of migrant legal status. With respect to induced abortion, we found significant differences across the three migration/legal-status groups: Native women showed the highest likelihood of having used an abortion, followed by fully regularized migrants and temporary/irregular migrants. Moreover, fully regularized migrants had a higher probability of aborting a pregnancy than temporary/irregular migrants only in the postmigration period. The detected patterns in abortion use by nativity and migrant legal status conform to two hypothesized pathways through which legal status may be conducive to greater abortion use in that context: migrants' assimilation into Russia's 'abortion culture' and their access to state-run abortion services. The survey data does not allow us to formally distinguish between the two pathways, but we argue that both operate simultaneously and should not be analytically separated. Notably, our findings differ from those of studies in other migrant-receiving contexts, where overall abortion use is much lower and where migrants typically have higher abortion rates than natives (e.g., Helström et al. 2003; Rasch et al. 2008; Picavet, Goenee, and Wijsen 2013; Rodriguez-Alvarez et al. 2016; González-Rábago et al. 2017). Again, however, due to data limitations, these studies could not be compared to our findings with respect to the role of legal status.

In contrast to considerable variation in induced abortion, we found no net difference in overall contraceptive prevalence across nativity and legal status. We propose that this pattern may reflect the relatively low pecuniary and access costs of modern contraception compared to those of induced abortion. With respect to contraceptive method choice, although the bivariate results alluded to some variations within the migrant subsample, in the multivariate analysis all migrants, regardless of legal status and other characteristics, were much more likely than natives to opt for the IUD - a relatively well-established method in the Soviet and early post-Soviet contraceptive tradition, especially in the Central Asian region. In comparison, natives 
were more inclined to use relatively 'novel' - even if generally less effective - shortterm methods such as the pill and condoms. Taken together with our findings on induced abortion, this finding illustrates the peculiar reproductive landscape in today's Russia, which is shaped by earlier historical legacies, cultural mores, and service availability, as well as institutional and structural divides that its immigration legal regime produces. Yet, although the Russian societal and reproductive context is unique in many respects, our findings regarding contraceptive use do align with some evidence produced by Western scholarship. For example, Garcés-Palacio et al. (2008), in their study in a US setting, detected substantial differences between Latina immigrants and nonimmigrant women in contraceptive method choice: Immigrants were more likely to use injectable contraception, while nonimmigrants preferred oral contraceptives or tubal ligation. As noted earlier, White, Ocampo, and Scarinci (2016) found culturally rooted concerns about oral contraceptives among recent Latina immigrants in the United States. Norms and preferences from the origin settings also influenced contraceptive choices of immigrants in Spain (Alvarez-Nieto et al. 2015).

Despite its pioneering nature, our study has limitations. The sample, while covering most typical sectors and occupations of migrant women, is not representative of the entire migrant population: Conducting a fully representative survey of migrants in contemporary Russia is impossible for both practical and political reasons. In addition, although unlike most studies of migrants we could distinguish between fully regularized and temporary/irregular migrants, information on precise timing of change in legal status is not available. As with most migrant-focused cross-sectional studies, we cannot account for selection into migration, which along with migrants' adaptation to the host environment may affect their abortion use and contraceptive behavior (cf., White and Potter 2013). Moreover, some selection into different legal-status paths may be a factor influencing reproductive choices. It is also possible that abortion use may have been disproportionately underreported by migrants due to certain cultural dispositions; however, the relative acceptability of abortion throughout the post-Soviet cultural space and the format of the interview assuring maximum trust between interviewers and respondents attenuate the potential scale of abortion underreporting. Moreover, there is no reason to suspect that the underreporting of abortion should vary between fully regularized and temporary/irregular migrants after holding other characteristics constant. Another limitation is that we could not directly link abortion and contraceptive use (e.g., through contraceptive failure). That several potentially time-varying covariates are measured at the time of survey also calls for caution in interpreting our results.

Finally, we should remind that international migrants' reproductive behavior and outcomes need to be seen within a broader context of migrants' long-term economic and family-building strategies (Lindstrom and Giorguli-Saucedo 2007; Parrado and 
Flippen 2012). Although our analysis, based on cross-sectional survey data, could not address these evolving contingencies and aspirations, it usefully informs future research efforts.

\section{Acknowledgments}

Funding for data collection was provided by the Eunice Kennedy Shriver National Institute of Child Health and Human Development (USA), Grant \#R01 HD058365 (supplement). Dr. Yoo's work was supported by a grant from the National Research Foundation of Korea (NRF-2017S1A3A2065967). 


\section{References}

Abashin, S. (2014). Migration from Central Asia to Russia in the new model of world order. Russian Politics and Law 52(6): 8-23. doi:10.2753/RUP1061-1940520 601.

Abbasi-Shavazi, M.J. and McDonald, P. (2000). Fertility and multiculturalism: Immigrant fertility in Australia, 1977-1991. International Migration Review 34(1): 215-242. doi:10.2307/2676018.

Agadjanian, V. (2002). Is 'abortion culture' fading in the former Soviet Union? Views about abortion and contraception in Kazakhstan. Studies in Family Planning 33(3): 237-248. doi:10.1111/j.1728-4465.2002.00237.x.

Agadjanian, V., Gorina, E., and Menjívar, M. (2014). Economic incorporation, civil inclusion, and social ties: Plans to return home among Central Asian migrant women in Moscow, Russia. International Migration Review 48(3): 577-603. doi:10.1111/imre.12117.

Agadjanian, V., Menjívar, C., and Zotova, N. (2017). Legality, racialization, and immigrants' experience of ethnoracial harassment in Russia. Social Problems 64(4): 558-576. doi:10.1093/socpro/spw042.

Agadjanian, V. and Qian, Z.C. (1997). Ethnocultural identity and induced abortion in Kazakhstan. Studies in Family Planning 28(4): 317-328. doi:10.2307/2137862.

Agadjanian, V. and Zotova, N. (2012). Sampling and surveying hard-to-reach populations for demographic research: A study of female labor migrants in Moscow, Russia. Demographic Research 26(5): 131-150. doi:10.4054/DemRes. 2012.26.5.

Akerman, E., Östergren, P.-O., Essén, B., Fernbrant, C., and Westerling, R. (2016). Knowledge and utilization of sexual and reproductive healthcare services among Thai immigrant women in Sweden. BMC International Health and Human Rights 16(1): 25. doi:10.1186/s12914-016-0100-4.

Andersson, G. (2004). Childbearing after migration: Fertility patterns of foreign-born women in Sweden. International Migration Review 38(2): 747-774. doi:10.1111/j.1747-7379.2004.tb00216.x.

Alvarez-Nieto, C., Pastor-Moreno, G., Luisa Grande-Gascón, M., and Linares-Abad, M. (2015). Sexual and reproductive health beliefs and practices of female immigrants in Spain: A qualitative study. Reproductive Health 12(1): 79. doi:10.1186/s12978-015-0071-2. 
Agadjanian \& Yoo: Abortion and contraception among migrants and natives in Russia

Avdeev, A. (1994). Contraception and abortion: Trends and prospects for the 1990s. In: Lutz, W., Scherbov, S., and Volkov, A. (eds.). Demographic trends and patterns in the Soviet Union before 1991. London/Laxenburg: Routledge/IIASA: 131146.

Betancourt, G.S., Colarossi, L., and Perez, A. (2013). Factors associated with sexual and reproductive health care by Mexican immigrant women in New York City: A mixed method study. Journal of Immigrant and Minority Health 15(2): 326333. doi:10.1007/s10903-012-9588-4.

Carter, M. (2000). Fertility of Mexican immigrant women in the United States: A closer look. Social Science Quarterly 81(4): 1073-1086.

Casillas, A., Bodenmann, P., Epiney, M., Gétaz, L., Irion, O., Gaspoz, J.M., and Wolff, H. (2015). The border of reproductive control: Undocumented immigration as a risk factor for unintended pregnancy in Switzerland. Journal of Immigrant and Minority Health 17(2): 527-534. doi:10.1007/s10903-013-99 39-9.

Castañeda, H. (2009). Illegality as risk factor: A survey of unauthorized migrant patients in a Berlin clinic. Social Science and Medicine 68(8): 1552-1560. doi:10.1016/j.socscimed.2009.01.024.

David, H.P. and Popov, A.A. (1999). Russian Federation and USSR successor states. In: David, H.P. and Skilogianis, J. (eds.). From abortion to contraception: A resource to public policies and reproductive behavior in Central and Eastern Europe from 1917 to the present. Westport: Greenwood Press: 223-277.

Deeb-Sossa, N. and Billings, D.L. (2014). Barriers to abortion facing Mexican immigrants in North Carolina: Choosing folk healers versus standard medical options. Latino Studies 12(3): 399-423. doi:10.1057/1st.2014.44.

Denisov, B.P. and Sakevich, V.I. (2014). Abortion in post-Soviet Russia: Is there any reason for optimism? Demographic Review 5: 50-68.

Denisov, B.P., Sakevich, V.I., and Jasilioniene, A. (2012). Divergent trends in abortion and birth control practices in Belarus, Russia, and Ukraine. PLOS ONE 7(11): e49986. doi:10.1371/journal.pone.0049986.

du Prey, B., Talavlikar, R., Mangat, R., Freiheit, E.A., and Drummond, N. (2014). Induced abortion and contraception use among immigrant and Canadian-born women in Calgary, Alta. Canadian Family Physician 60(9): e455-e463. 
Farid, H., Siddique, S.M., Bachmann, G., Janevic, T., and Pichika, A. (2013). Practice of and attitudes towards family planning among South Asian American immigrants. Contraception 88(4): 518-522. doi:10.1016/j.contraception.2013. 03.011 .

Garcés-Palacio, I.C., Altarac, M., and Scarinci, I.C. (2008). Contraceptive knowledge and use among low-income Hispanic immigrant women and non-Hispanic women. Contraception 77(4): 270-275. doi:10.1016/j.contraception.2007.12. 008 .

Gonzalez, E.U., Sable, M.R., Campbell, J.D., and Dannerbeck, A. (2010). The influence of patriarchal behavior on birth control access and use among recent Hispanic immigrants. Journal of Immigrant and Minority Health 12(4): 551558. doi:10.1007/s10903-009-9272-5.

González-Rábago, Y., Rodriguez-Alvarez, E., Borrell, L.N., and Martín, U. (2017). The role of birthplace and educational attainment on induced abortion inequalities. BMC Public Health 17: 69. doi:10.1186/s12889-016-3984-y.

Gorina, E., Agadjanian, V., and Zotova, N. (2017). Migrant women's economic success in Russia: Objective reality and subjective assessment. Journal of Ethnic and Migration Studies 2017. doi:10.1080/1369183X.2017.1333410.

Helström, L., Odlind, V., Zätterström, C., Johansson, M., Granath, F., Correia, N., and Ekbom, A. (2003). Abortion rate and contraceptive practices in immigrant and native women in Sweden. Scandinavian Journal of Public Health 31(6): 405-410. doi:10.1080/14034940210165181.

Henshaw, S.K. (1986). Induced abortion: A worldwide perspective. Family Planning Perspectives 18(6): 250-254. doi:10.2307/2134947.

Jilozian, A. and Agadjanian, V. (2016). Is induced abortion really on the decline in Armenia? Studies in Family Planning 47(2): 163-178. doi:10.1111/j.1728-4465. 2016.00053.x.

KDHS (2013). Kyrgyz Republic Demographic and Health Survey 2012. Bishkek and Calverton: National Statistical Committee (Kyrgyz Republic), Ministry of Health (Kyrgyz Republic), and ICF International.

Khusenova, N. (2013). The feminization of Tajik labor migration to Russia. In: Laruelle, M. (ed.). Migration and social upheaval as the face of globalization in Central Asia. Leiden: Brill Publishers: 355-375. doi:10.1163/97890042495 09022. 
Lindstrom, D.P. and Giorguli Saucedo, S. (2002). The short-and long-term effects of US migration experience on Mexican women's fertility. Social Forces 80(4): 1341-1368. doi:10.1353/sof.2002.0030.

Lindstrom, D.P. and Giorguli Saucedo, S. (2007). The interrelationship between fertility, family maintenance, and Mexico-US migration. Demographic Research 17(28): 821-858. doi:10.4054/DemRes.2007.17.28.

Malakhov, V.S. (2014). Russia as a new immigration country: Policy response and public debate. Europe-Asia Studies 66: 1062-1079. doi:10.1080/09668136.2014. 934140 .

Malin, M. and Gissler, M. (2008). Induced abortions among immigrant women in Finland. Finnish Journal of Ethnicity and Migration 3(1): 2-12.

Manderson, L., Kelaher, M., Woelz-Stirling, N., Kaplan, J., and Greene, K. (2002). Sex, contraception, and contradiction among young Filipinas in Australia. Culture, Health, and Sexuality 4(4): 381-391. doi:10.1080/1369105021000041 034.

Mayer, J. and Riphahn, R.T. (2000). Fertility assimilation of immigrants: Evidence from count data models. Journal of Population Economics 13(2): 241-261. doi: $10.1007 / \mathrm{s} 001480050136$.

Mogilevkina, I., Markote, S., Avakyan, Y., Mrochek, L., Liljestrand, J., and Hellberg, D. (1996). Induced abortions and childbirths: Trends in Estonia, Latvia, Lithuania, Russia, Byelorussia, and the Ukraine during 1970 to 1994. Acta Obstetricia et Gynecologica Scandinavica 75: 908-911. doi:10.3109/000163496 09055026.

Parrado, E.A. (2011). How high is Hispanic/Mexican fertility in the United States? Immigration and tempo considerations. Demography 48(3): 1059-1080. doi:10.1007/s13524-011-0045-0.

Parrado, E.A. and Flippen, C.A. (2012). Hispanic fertility, immigration, and race in the twenty-first century. Race and Social Problems 4(1): 18-30. doi:10.1007/ s12552-012-9063-9.

Picavet, C., Goenee, M., and Wijsen, C. (2013). Characteristics of women who have repeat abortion in the Netherlands. The European Journal of Contraception and Reproductive Health Care 18(5): 327-334. doi:10.3109/13625187.2013.820824. 
Philipov, D., Andreev, E., Kharkova, T., and Shkolnikov, V. (2004). Induced abortion in Russia: Recent trends and underreporting in surveys. European Journal of Population 20(2): 95-117. doi:10.1023/B:EUJP.0000034499.24658.7a.

Poncet, L.C., Huang, N., Rei, W., Lin, Y.C., and Chen, C.Y. (2013). Contraceptive use and method among immigrant women in France: Relationship with socioeconomic status. The European Journal of Contraception and Reproductive Health Care 18(6): 468-479. doi:10.3109/13625187.2013.835394.

Popov, A.A. (1991). Family planning and induced abortion in the USSR: Basic health and demographic characteristics. Studies in Family Planning 22(6): 368-377. doi: $10.2307 / 1966450$.

Popov, A.A., Visser, A.P., and Ketting, E. (1993). Contraceptive knowledge, attitudes, and practice in Russia during the 1980s. Studies in Family Planning 24(4): 227235. doi: $10.2307 / 2939190$.

Quelopana, A.M. and Alcalde, C. (2014). Exploring knowledge, belief, and experiences in sexual and reproductive health in immigrant Hispanic women. Journal of Immigrant and Minority Health 16(5): 1001-1006. doi:10.1007/s10903-0139807-7.

Rasch, V., Gammeltoft, T., Knudsen, L.B., Tobiassen, C., Ginzel, A., and Kempf, L. (2008). Induced abortion in Denmark: Effect of socioeconomic situation and country of birth. European Journal of Public Health 18(2): 144-149. doi:10.1093/eurpub/ckm112.

Ratha, D., Eigen-Zucchi, C., and Plaza, S. (2015). Migration and Remittances Factbook. Washington, D.C.: World Bank.

Reeves, M. (2013a). Clean fake: Authenticating documents and persons in migrant Moscow. American Ethnologist 40(3): 508-524. doi:10.1111/amet.12036.

Reeves, M. (2013b). Becoming 'black' in Moscow: Documentary regimes and migrant life in the shadow of law. In: Malakhov, V. (ed.). Citizenship and immigration: Conceptual, historical, and institutional dimensions. Moscow: Russian Academy of Sciences: 146-177.

Remennick, L. (1991). Epidemiology and determinants of induced abortion in the USSR. Social Science and Medicine 33(7): 841-848. doi:10.1016/0277-9536 (91)90389-T.

Remmenick, L. (1993). Patterns of birth control. In: Kon, I. and Riordan, J. (eds.). Sex and Russian society. Bloomington: Indiana University Press: 45-63. 
Rocheva, A. and Varshaver, E. (2017). Gender dimension of migration from Central Asia to the Russian Federation. Asia-Pacific Population Journal 32(2): 87-135.

Rodriguez-Alvarez, E., Borrell, L.N., González Rábago, Y., Martín, U., and Lanborena, N. (2016). Induced abortion in a Southern European region: Examining inequalities between native and immigrant women. International Journal of Public Health 61(7): 829-836. doi:10.1007/s00038-016-0799-7.

Rosstat (2012). Reproductive Health Survey, Russia 2011: Executive summary. Moscow: Federal State Statistics Service of the Russian Federation, Ministry of Health of the Russian Federation, UNPFA, CDC.

Schoevers, M.A., van den Muijsenbergh, M.E., and Lagro-Janssen, A.L. (2010). Illegal female immigrants in the Netherlands have unmet needs in sexual and reproductive health. Journal of Psychosomatic Obstetrics and Gynecology 31(4): 256-264. doi:10.3109/0167482X.2010.528090.

Sedgh, G., Singh, S., Henshaw, S.K., and Bankole, A. (2011). Legal abortion worldwide in 2008: Levels and recent trends. International Perspectives on Sexual and Reproductive Health 37(2): 84-94. doi:10.1363/3708411.

Stloukal, L. (1999). Understanding the 'abortion culture' in Central and Eastern Europe. In: David, H.P. (ed.) From abortion to contraception: A resource to public policies and reproductive behavior in Central and Eastern Europe from 1917 to the present. Westport: Greenwood Press: 23-27.

TDHS (2013). Tajikistan Demographic and Health Survey 2012. Dushanbe and Calverton: Statistical Agency (Tajikistan), Ministry of Health (Tajikistan), and ICF International.

Tyurukanova, E.V. (2011). Migrant women from the Commonwealth of Independent States in Russia. Moscow: Maks Press.

UHES (2004). Uzbekistan Health Examination Survey 2002. Calverton: Ministry of Health (Uzbekistan), State Department of Statistics (Uzbekistan), Ministry of Macroeconomics and Statistics (Uzbekistan), and ORC Macro.

United Nations (2016). International migrant report 2015. New York: United Nations, Department of Economic Affairs.

Viladich, A. (2012). Beyond welfare reform: Reframing undocumented immigrants' entitlement to health care in the United States. Social Science and Medicine 74(6): 822-829. doi:10.1016/j.socscimed.2011.05.050. 
White, K.L. and Potter, J.E. (2013). Patterns of contraceptive use among Mexicanorigin women. Demographic Research 28(41): 1199-1212. doi:10.4054/Dem Res.2013.28.41.

White, K., Ocampo, M., and Scarinci, I.C. (2016). A socioecological approach for examining factors related to contraceptive use among recent Latina immigrants in an emerging Latino state. Women and Health 29: 1-18.

Wiebe, E. (2013). Contraceptive practices and attitudes among immigrant and nonimmigrant women in Canada. Canadian Family Physician 59: e451-e455.

Willen, S.S. (2012). Migration, 'illegality,' and health: Mapping embodied vulnerability and debating health-related deservingness. Social Science and Medicine 74(6): 805-811. doi:10.1016/j.socscimed.2011.10.041.

Wolff, H., Stalder, H., Epiney, M., Walder, A., Irion, O., and Morabia, A. (2005). Health care and illegality: A survey of undocumented pregnant immigrants in Geneva. Social Science and Medicine 60(9): 2149-2154. doi:10.1016/j.socsci med.2004.12.007.

Zakharov, N. (2015) Race and racism in Russia. London: Palgrave Macmillan. doi:10.1057/9781137481207.

Zotova, N. and Agadjanian, V. (2014). Female migration to Russia from Central Asian countries: Migrants researching migrants. In: Hohmann, S., Mouradian, C., Serrano, S., and Torrez, J. (eds.). Development in Central Asia and the Caucasus. Migration, democratization and inequality in the post-Soviet era. London: I.B.Tauris: 242-263. 
Agadjanian \& Yoo: Abortion and contraception among migrants and natives in Russia 